Humphreys, C. and Jacobs, S. (2004)

'Domestic Violence and the Politics of Trauma', Women's Studies International Forum 27 (5-6) 559-570

\title{
Domestic Violence and the Politics of Trauma
}

Dr Cathy Humphreys, School of Health and Social Studies, University of Warwick

Dr Stephen Joseph, Department of Psychology, University of Warwick

$\underline{\text { Address for Correspondence: }}$

Professor Cathy Humphreys

School of Nursing and Social Work

University of Melbourne

Melbourne, Victoria. 3010

c.f.humphreys@warwick.ac.uk

Ph. 44 (0)24 76524922

$44(0) 1908615182(\mathrm{hm})$

Fax 4 (0)24 76524415 


\section{Domestic Violence and the Politics of Trauma}

Posttraumatic Stress Disorder (PTSD) has had a chequered history in relation to gender-based violence and specifically domestic violence. There is evidence that a significant proportion of women who are abused suffer from PTSD. However, there remains controversy about whether this is a useful and progressive concept on which to base intervention. Mainstream mental health services in the UK have shown little 'take up', while women’s services supporting survivors also remain ambivalent, though for different reasons. Clinical psychology has been where the concept has been embraced. This paper highlights aspects of Judith Herman’s original intervention framework which have remained undeveloped, specifically the attention to social support and the need for an active social movement. These ideas have been marginalized in the development of professional and individualised approaches to survivors. It is suggested that re-invigorating these ideas would enhance the work with survivors and provide greater resonance with the underpinnings of work with women’s services.

Keywords: PTSD; domestic violence; mental health; social movements; social support 


\section{Domestic Violence and the Politics of Trauma}

The acceptance of Posttraumatic Stress Disorder (PTSD) as a useful concept with which to understand and intervene in work with trauma victims/survivors has had an uneven history. This is no more so than in the areas of gender based violence, particularly domestic violence, where women have been the predominant victims. Within the UK, this remains a contested concept and its relevance and 'up take' in these areas remains on the margins of intervention both within mainstream mental health services, but also (though for different reasons) on the edges of women’s services in the voluntary sector which support survivors. The home which PSTD intervention has found more generally has been within clinical psychology services, though few domestic violence survivors in the UK have access to these services. It is argued in this paper that Judith Herman's earlier ideas (1992) about the significance of social support and the role of social movements have been marginalized within current trauma intervention. In this process, the positive role of broader based intervention in the recovery path for abused women has been undermined, and subjugated to the dominant, individualising discourses within therapeutic practice. Emerging ideas and practices in both trauma intervention and the wider movement to support survivors of abuse are discussed.

\section{PTSD and domestic violence - the evidence base}

The area of domestic violence is chosen because there is quite substantial evidence of posttraumatic stress amongst a significant group of survivors. Posttraumatic stress disorder which will be discussed further in the next section, refers to a constellation of symptoms which include: re-living the traumatic events through flashbacks or nightmares; avoidance or numbing of responses; and hypervigilance or increased 
arousal evidenced by irritability, inability to concentrate, and inability to get to sleep or stay asleep (Murphy, 1997).

Several meta analyses are now available of the research studies on PTSD and domestic violence. An overview by Jones et al, (2001) of 42 studies found worryingly high rates of PTSD similar to those found by Golding (1999) and Cascardi et al (1999) in their overviews of 11 studies. These rates varied from $31 \%$ to $84 \%$ (Gleason, 1993; Kemp et al, 1995) depending on the site from which the sample was drawn. Not surprisingly, women in refuges showed a higher rate of PTSD than those drawn from community based services(Kemp et al. 1995; Saunders, 1994).

The links of PTSD to rape and sexual violence has been given wider acknowledgement and recognition (Bisson and Shepherd, 1995), as the trauma of rape is more easily understood by the broader community. Studies vary in the extent to which women name sexual violence as part of their experience of domestic violence. Campbell (1998) found that 40-45\% of women living in a refuge had suffered sexual violence, though this is high compared with $27 \%$ found in a more broadly based Canadian prevalence study (Johnson, 1998). The British Crime Survey which relies on victim responses found that $75 \%$ of rape and sexual assault is committed by a current or former partner (Myhill and Allen, 2002). Given these high levels of sexual assaults within intimate relations, the significant link between domestic violence and PTSD is unsurprising.

In both the UK and the US, the vulnerability of black and minority ethnic women to the undermining of their mental health through domestic violence has been 
highlighted. This is particularly evident in the over-representation of women in relation to suicide attempts and self-harm (Stark and Flitcraft, 1995; Soni-Raleigh, 1996; Bhugra, 1999). However, qualitative studies describe flashbacks, panic attacks and other classic symptoms of trauma as an integral part of these responses (Batsleer, 2002; Yazdani, 1998).

In spite of the high levels of distress that these data point to, the response to trauma intervention in the UK has been limited for this group of survivors. The issue takes on particular relevance in the context of survivors demanding more services which intervene appropriately to alleviate their individual emotional pain and raises questions about the direction this might take. For example, a recent survey of 180 women using domestic violence services, of which $25 \%$ were black and minority ethnic women, showed that counselling services were considered one of the highest priorities for service development (Humphreys and Thiara, 2002). This is a finding supported by Batsleer (2002) in their study of the needs of 'minoritised' women which found that services to provide emotional support for recovery were limited, though highly valued where they were provided.

In short, domestic violence survivors are a group who currently suffer high rates of PTSD, but in the UK currently have little access to trauma services. They therefore provides a rich site through which a more general discussion of the politics of trauma intervention can be explored. 


\section{Gender-Based Violence and PTSD}

The politics of PTSD applied to women's experiences of violence and sexual assault do not stand outside the development of PTSD as a concept recognised as a diagnostic category within the DSM framework. Through this 'diagnostic' gateway, legitimacy is given not only to aspects of work within the helping professions but also access to health and counselling services, compensation and insurance. It is one of the institutionalised sites through which the dominant discourses within mental health are constructed and one where some feminists have energetically fought for recognition of the trauma which women and children suffer as a result of violence and abuse within the family. It is therefore worthwhile outlining briefly the history of some aspects of the diagnostic category of PTSD introduced within DSM-III (American Psychiatric Association, 1980).

Initially the strongest group pressuring for the recognition of trauma as a legitimate DSM category came from those working with war veterans. They described patterns of symptoms that arose as a result of the psychologically traumatic events of combat - a direct link between external trauma and the expression of psychological pain. Their work culminated in the DSM-III recognising PTSD as symptoms grouped into three sections: (1) re-experiencing of the traumatic event; (2) numbing of responsiveness to, or reduced involvement in the external world; and (3) a miscellaneous section which included memory impairment, difficulty concentrating, hyperalertness or an exaggerated startle response. It was not only the set of responses which were crucial in defining the category, but Criterion A specified that an event also needed to be classified as traumatic - 'outside the range of normal human experience'. 
Feminists such as Judith Herman (1992) mounted a concerted campaign to gain recognition that the symptoms of trauma which war veterans experienced had much in common with the reactions by women (and a minority of men) within the domestic sphere both as survivors of childhood sexual abuse and domestic violence. From Herman's clinical position within a major hospital setting, this acknowledgement would represent a major step in overturning pejorative labels such as borderline personality disorder which were being used to unhelpfully describe women’s symptoms of complex trauma reactions (Herman, 1992). She argued convincingly that these inappropriate diagnoses allowed little scope for treatment or recognition of the history of the pain associated with the 'symptoms of abuse'. The lack of understanding of the traumatic experience of psychological captivity in which a reign of terror could be instigated meant that victim blaming was rampant through inappropriate labelling of the victims’ psychopathology divorced from their experiences of trauma. Explicitly naming the trauma women had suffered, and outlining a mode of intervention which positively engaged both survivor and clinician in 'working through' the history of abuse and survival was a radical and potentially libratory act within the conservative psychiatric establishment.

Campaigning for recognition of the trauma experienced by a very significant group of women survivors who were over-represented within the mental health system, also represented a dent in the processes through which a group of white, male professionals had been able to name and speak with authority on the experiences of others. Such advocacy proved essential not only in the positive recognition of the normal patterns of traumatic response, but also in preventing the inclusion of such categories as 'masochistic personality disorder' which could have easily been used to 
inappropriately label women’s experiences of trauma (Herman, 1992.p.117). There have also been other ways in which feminists (and others) have contributed to the developing trauma discourse and to the DSM categorisation. This has included challenging the ways in which an event comes to be classified as traumatic (Burstow, 1992; Brown, 1995).

While some events, such as an aeroplane disaster or ferry sinking, were clearly understood to fulfil criterion A as specified in DSM-III and DSM-III-R, there remained much debate on whether other events, such as the death of a spouse through cancer, or chronic exposure to oppressive situations such as on-going racism, met the criterion. If a person can develop all the emotional and behavioural symptoms of PTSD without having experienced an event outside the range of usual human experience, then it could be argued that the definition of what constitutes a traumatic event must change. Particularly, when individuals live with constant oppression or discrimination, they may be living with an everyday occurrence, rather than an exceptional event (Brown, 1995). It was argued that what was important was how the person perceived the event and thus, criterion A should include reference to these subjective experiences. Clearly, what is traumatic to one person may not be so to another.

Other arguments were also put forward and the DSM-IV reformulated criterion A as: (1) exposure to a traumatic event coupled with (2) the person's reaction to it. In doing so, a significant step was taken in validating survivor's subjective experiences, outside others (usually professionals), definitions of what should constitutes a traumatic event. 
Behind these changes in the discourse of diagnosis there are also shifts in the politics of 'take up' and the politics of intervention. PTSD is more than a description and the acknowledgement of a set of symptoms, it represents changes in the understandings, needs and language used to describe survivors of trauma and their path to recovery. There are several inter-related aspects to be explored which both construct and define the work in the trauma area for domestic violence survivors. Firstly, how trauma intervention has developed, and the areas of work which have become subjugated and ignored. Secondly, the related issue of the different ways in which the concept of PTSD itself has been marginalized or embraced and by whom.

\section{Attention to 'the social’?}

The DSM framework is not a neutral tool. The defining and categorisation of human experience by a group of professionals who legitimate particular patterns of behaviour related to specific norms takes the process of naming out of the hands of those who experience the behaviour - in this case domestic violence survivors. It also ushers in particular practices by professionals whose work becomes legitimated. In this process selected concepts associated with trauma and trauma intervention are either neglected or colonised.

Again, it is worth returning to Herman (1992) as a key proponent not only of the original naming of PTSD in relation to women survivors of various forms of intimate violence, but also the components of intervention. She wrote with great clarity about the 'dialectic of trauma', in which the survivor simultaneously needs to both deny the reality of an atrocity and to remember and speak of their experience. She argued that there are parallel processes within the social context. The need for a community or a 
culture to deny the presence of violence, abuse and disaster runs alongside the imperative to collectively acknowledge these destructive aspects of the society if collusion and denial and hence abuse are not to be perpetuated. Particularly where the perpetrators of violence are powerful and influential, the ability to silence, shame and discredit the traumatic reality of their victims gains ascendancy. Such a propensity led Herman (1992) to speak of the importance of the relationship context and the need for an active political movement to support individual survivors.

To hold traumatic reality in consciousness requires a social context that affirms and protects the victim and that joins victim and witness in common alliance. For the individual victim, this social context is created by relationships with friends, lovers and family. For the larger society, the social context is created by political movements that give voice to the disempowered (Herman, 1992, p.9).

Thus, an essential aspect of the healing process lies not only in individualised counselling, but in the reconnecting of traumatised individuals to their communities and a social movement which continues to bring testimony to their experience.

There is an obvious tension between the original ideas about the recovery needs of survivors mentioned above and the positioning of trauma services within the mental health professions. In the next sections we explore the various ways in which the discourse in relation to domestic violence survivors has been developed particularly within the UK. 


\section{Continuing Neglect with Psychiatry}

The original impetus for recognition of PTSD in relation to women survivors of gender-based violence lay in wanting to influence the mainstream mental health agenda to bring about a more appropriate intervention. Paradoxically, there remains a reluctance to engage with the concept by the psychiatric profession (McFarlane, 2000). The significance, particularly of adult trauma continues to be marginalized in relation to mental health work in spite of the over-representation of this group within the mental health system. McFarlane points to the lack of attention within the mainstream undergraduate curricula or post-graduate training, and the consistent failure within psychiatric settings to identify the obvious presence of PTSD (McFarlane, 2000; Zimmerman and Mattia, 1999). Even pharmacological treatment (Davidson and van der Kolk, 1996) has not seen a significant ‘take up’. Treatment requires defining the trauma symptoms in the first instance, and hence has not been utilized to the extent one might have expected in a psychiatric establishment where medication is such a central treatment intervention.

While stating that there remains neglect within psychiatry and mental health services, it would be wrong to not acknowledge that there has been some increase in attention to PTSD in the past five years. Taking the British Journal of Psychiatry and Advances in Psychiatric Treatment as a barometer of the discourse within the mainstream of psychiatry in the UK, there is clearly emerging interest in the area. There have been 142 articles in the past four years which mention PTSD. However, only two of these articles focused directly on domestic violence and aspects of PTSD (Vostanis, 2002; Coid et al, 2003) with a further small number on child sexual abuse (Sequeirqa and Hollins, 2003; Trowell et al, 2002). Given that the overviews of 
research on PTSD shows particularly high rates amongst domestic violence survivors (Golding, 1999; Cascardi et al, 1999) this marginalisation within the mainstream of mental health services raises issues of concern, particularly when domestic violence survivors constitute a very significant group of people using psychiatric services (Tham et al, 1995; Gondolf, 1998; Barron, 2004). Such a contention is further supported by policy documents (Department of Health, 2002) and a survey of members of the Women’s Mental Health Network (Williams and Coppermen, 2002) which indicated that survivors of abuse and violence, women from black and ethnic minority groups and women with complex or dual diagnosis are seen as the groups currently most vulnerable to neglect within mental health services.

Unfortunately, it is not only neglect, which women within the psychiatric system are open to when the causal role of violence in relation to their 'symptoms' is not acknowledged. Misdiagnosis, inappropriate medication, and collusion with abuse (and the perpetrator) becomes common-place. For black and minority women in the UK there are particular issues related to the over-use of compulsory measures and the stigma and shame which may have serious repercussions for them in relation to marriage arrangements and their position in the community (Yazdani, 1998). Moreover, the flow on negative effects of being named with mental health problems in child contact and other court proceedings may be an unfortunately high price to pay for inappropriate 'care' within the mental health system (Humphreys and Thiara, 2003). While feminists such as Burstow (2003) argue that we should 'give up on psychiatry', we would argue that given the numbers of survivors using the mental health system, that there is a case to be made for continued awareness raising and lobbying of the psychiatric profession for recognition of the symptoms of trauma as a 
result of gender based violence. In the UK, given the current priority within many health trusts that psychiatrists prioritise services for those suffering acute and serious mental health problems (read psychosis), this may mean that women will be referred to other (often more appropriate) services if they are available within the area, rather than being treated by psychiatrists directly. It opens up the possibility for instance, of health trusts commissioning voluntary sector organisations or GP practices to provide counselling services for survivors.

\section{A Home within Clinical Psychology}

Whereas psychiatry has continued to ignore PTSD as a useful concept with which to respond to women suffering from trauma, clinical psychology has tended to embrace the concept. PTSD struck a chord within the less medically-based arena of counselling, clinical psychology and the helping professions more generally. It spoke 'the truth' about the experiences of a very significant group of people who come to counsellors and therapists seeking help. In the US particularly, business boomed and an industry began to develop around intervention in PTSD ( Babcock and McKay, 1995). Specialist techniques burgeoned. Cognitive behavioural techniques (Herbert and Wetmore, 1999; Resick and Jordan, 1988), critical stress debriefing (Mitchell, 1983), eye movement desensitisation reprocessing (EMDR) (Shapiro, 1989; 1995), psychodynamic therapy (Lindy, 1996; Marmar et al, 1995) all were considered to have a role to play. Comparative research evaluated the efficacy of different interventions (Brom et al, 1989) and robust debate has ensued in which protagonists from each area continue to highlight the value of particular methods and techniques (Resick, 2001). Whatever the approach, the effect has been to highlight the professional and specialist nature of intervention. Therapy has been overwhelmingly 
individually based and works very specifically to relieve the symptoms which create such significant distress for trauma survivors.

Interestingly, in spite of the development of clinically based trauma services within the UK, domestic violence survivors and rape victims have little access to such services except through private funding arrangements. Rape crisis services are chronically under-funded, voluntary sector refuge and outreach services employ few counsellors, and GPs are generally not referring survivors to the few precious counselling services available through Primary Health Care settings. This then raises the question of whether such neglect deprives women of their right to the best available services, or alternatively whether the poverty of funding has the unexpected benefit of keeping women's path to recovery out of the hands of professional psychologists? It can be argued for instance, that women's services have been seeing and responding to traumatised women for many years and that women have consistently rated the support they have received from these services very highly. It would be important therefore not to under-estimate this role, and to recognise that it is not only professional, clinical psychologists who intervene and provide support for the trauma experiences of domestic violence survivors. In exploring this question further, it is worth pausing on the role of social support in relation to PTSD intervention.

\section{The Role of Social Support in Clinical Psychology}

Within the literature and research on posttraumatic stress used by psychologists there has actually been a significant amount of attention to the issues of social support. A group of research studies show in different ways that survivors of trauma are assisted 
by supportive rather than critical or hostile relationships with family members and partners (Coker et al, 2002; Tarrier et al, 1999). Resick (2001) provides an overview of research on the relationship between social support and PTSD. While highlighting the complexity of this concept, her overview provides compelling evidence that survivors of trauma with high social support had significantly lower rates of PTSD than those with poor support (Boscarino, 1995; Davidson et al, 1991). More recent studies have suggested that the findings on social support may be gendered with women responding particularly strongly to negative responses from family and friends (Andrews et al, 2003).

This may be of particular significance for black and minority ethnic women who consistently report the importance of their sense of 'belonging' and the intense feelings of distress associated with sometimes needing to choose between continuing to live with violence or leaving their family and community (Rai and Thiara, 1997; Bastleer, 2002). The study by Humphreys and Thiara (2002) showed that in the medium to long term, black and minority ethnic women suffered significantly higher levels of isolation and lack of social support than white women, highlighting an area of significant social disadvantage.

While, this research and the work by Herman (1992) on 'connectivity' indicate that social support is a significant factor in recovery or buffering against the development of PTSD, the individual intervention focus which has become so popular in the treatment of trauma survivors tends to underplay the centrality of this aspect of the research on social support. This issue is of particular significance when working with survivors of intimate violence where a key strategy in the abuse has usually been the 
isolation of the woman through the steady erosion of her support network. The attention to the skills involved in supporting the development of social networks which has been a feature of relationship counselling (Laing, 2001; Sanders, 1992), has not been a prominent aspect of trauma intervention.

Similarly, while support groups are clearly seen to have a place in some intervention areas to support survivors (Laing, 2001; Flannery et al, 2000), this aspect of the work in relation to PTSD has been given little attention relative to the discussion and development of EMDR, critical incident de-briefing and cognitive behavioural therapy. This selective development highlight the processes through which some aspects of the PTSD discourse are developed and others disregarded.

\section{Ambivalence from Women’s Services}

While clinical psychology may have embraced the concept of PTSD, women's services supporting survivors in the UK, like psychiatry, though for different reasons, have been reluctant, or ambivalent about the use of this language in their work. Different views have emerged from within the women’s movement based broadly upon different political stances (Berg, 2002). Liberal feminists have generally seen the naming of PTSD as progressive: 'a non-pejorative description of events and responses rather than a stigmatising process' (Berg, 2002 p.58) and one which validates the survivors subjective experiences. Their attitudes support the earlier work of feminists who sought to have PTSD recognised as a legitimate form of intervention for abuse survivors. There is therefore a clear tradition within feminist praxis which supports and continues to support positive intervention using PTSD as a foundational concept through which to understand the patterns of trauma (Harvey, 
1996; Jones et al, 2001). Within the US, many of the women organising the services for survivors and contributing to the professionalisation of those services would support the referral of women to clinical psychologists or bringing those services into voluntary sector organisations. In fact, it can be argued that even the counselling services in refuges which do not work from clinical models of trauma counselling, will nevertheless be actively intervening with trauma victims and there has been no suggestion that survivors are unhappy with these services. In these cases, there maybe a false dichotomy between the voluntary sector and the role of clinical psychologists, many of whom would emphasise their credentials as feminists supporting survivors.

Radical feminism has been the most critical of the use and abuse of PTSD (Anderson, 1996; Burstow, 2003; Brown, 1995). The process through which individual pain is named, particularly if it involves DSM IV terminology such as PTSD, is seen to have the potential to pathologise the survivor and place the power for her recovery in the hands of the professional counsellor (Dutton, 1992). While they have been critical about the ways in which a generic concept of PTSD ignores the significance of gender issues, their greatest concern lies with the individualising processes within the psychiatric discourse and the unequal power relations in the counselling relationship (Carlson, 1997). Such practices they point out, are complicit in not only pathologising women, but creating a focus on the individual woman's response to her situation. This focus diverts attention from both the offender and the wider social context which creates the circumstances for the endemic violence against women. Questions continue to arise about whether the overall affect of individualised counselling approaches turn victims into clients rather than survivors who have a 
capacity not only to recover from the effects of abuse, but who also may have a reciprocal role to play with other survivors and for some, a political role in keeping the on-going issues of social justice in the public arena (Profitt, 2000). In this sense, while PTSD might represent some progress from the 'dumping ground' of personality disorder, the discourse which includes the relations of power/knowledge and the individualising and introspective practices of psychiatry remains problematic (see Taft, 2003).

These concerns highlight the ways in which the original intervention framework conceptualised by Herman (1992) has been selectively used. Issues which may have had a greater resonance with organisations supporting survivors have been lost. The significance and the emphasis on social support and the reconnection of the individual survivor to a community and the pivotal role of social movements in supporting the voice of the survivor have been lost, or at least minimised in importance in the development of the PTSD discourse. Such selectivity exemplifies the ways in which aspects of a discourse are either supported and strengthened through the professions or alternatively neglected and diminished.

\section{The Role of Social Movements}

It would appear that while the role of social support has had minimal development within PTSD intervention, the aspect of the discourse which has been most marginalized by the professionalised response to PTSD has been the significant role that social movements have to play in creating the social context through which survivors can find a space for affirmation and justice. While for some trauma victims this may not be an issue, in the arena of violence against women, where the context of 
the traumatic event/s involve shame, humiliation and often criminal acts of violence against a background of a chronic social problem, the role of a supportive social movement has particularly significance.

Social movements can be defined as organised efforts to promote or resist change in society that rely, at least in part, on non-institutionalised forms of political action (Marx and McAdam, 1994 p.3). An aspect of the 'new social movements' instigated in the seventies and continuing in different forms to the present day, is the attention to social justice, and the challenge to oppression and the processes of discrimination (Thompson, 2002). These are pivotal issues for abuse survivors where it can be argued that there is a widespread tendency for denial and minimisation to dominate and subjugate stories of abuse and violence particularly when they disrupt and undermine strongly held beliefs about social institutions such as the family (Herman, 1992). Providing an alternative discourse which validates the survivor's experience, recognises her right to justice, and re-casts the shame and humiliation of the abuse experience into a story which affirms her strength and resilience in the face of a violence, it could be argued is an essential, though not necessarily measurable role of the movements which support abuse survivors.

In the UK, it is difficult to point to a women's movement as such. There are several different 'network of organisations' which it could be argued constitute the diverse face of contemporary social movements (Melucci, 1989) through which domestic violence survivors receive support. In the UK, the women's refuges under the umbrella of the Women's Aid Federations of England, Wales, Scotland and Northern Ireland share a number of common principles in their work with survivors which 
provide the platform for political lobbying. Separate networks exist for black and minority organisations such as IMKAAN (Asian refuges network) and Southall Black Sisters which provide specific representation for the interests of these groups, but which often create alliances with Women's Aid for political purposes. Shared values include: a strong belief in mutual self help; a strengths based approach to intervention; a commitment to advocacy; acknowledgement that women's individual stories are part of a wider social context in which violence against women is an endemic pattern; and a commitment to involving survivors in the organisation of services (Hague et al, 2003). Historically, ideas have been drawn from radical feminism, and the provision of professional counselling services has therefore not been a priority. There continues to be ambivalence within organisations about how such services link with, or alternatively undermine the commitments to self-help and advocacy. Nevertheless, following the demands of survivors and given the commitments of many of these organisations to user involvement, many refuges are now providing some limited counselling services (Abrahams, 2004).

It is worth digressing for a moment on the issue of counselling services and their role in relation to abuse survivors. This article has raised concerns about how professional trauma services may be developing in ways which have little resonance with organisations which have traditionally supported abuse survivors. However, just as there are changes in these voluntary sector services, there are also shifts and changes in the approach to trauma.

Undoubtedly, Posttraumatic Stress Disorder is the language of psychology rather than the language of survivors and language constructs our perceptions of a phenomena. 
While it has been argued that PTSD may represent progress from previous terminology through acknowledging directly the link to a situational trauma rather than an intrinsic aspect of personality, the term 'disorder' also expresses a notion of pathology, writ large by its inclusion within the DSM framework. In contrast, there is now a growing body of research testifying to the phenomenon of what has become known as posttraumatic growth. Posttraumatic growth refers to positive changes following trauma, and it has been found that between 30 and 90 per cent of survivors report at least some positive changes following trauma (see, Tedeschi, \& Calhoun, 1995; Tedeschi, Park, \& Calhoun, 1998; Joseph et al, 1993).

Recognition of resilience (McFarlane and Yehuda, 2000) and growth provide a bridge to ideas which are central to the social movement to support survivors of abuse. This language constructs a perspective which both names the trauma/pain and acknowledges the possibility of positive change. Potentially, these ideas now circulating within the literature and practices of trauma services resonate with ideas which have had credence within the movement supporting abuse survivors since its inception. A strength based approach to domestic abuse survivors which builds upon their capacity for self-determination and respects their survival skills is not new territory for work with women who have been traumatised, but has a long history within the movement to support survivors (Burstow, 1992).

It is not only the issues in relation to PTSD which are changing. The social movement which provides testimony to the experience of abuse survivors is also changing. At one level, it is possible to point to a weakening of grassroots social movements, including the women's movement which initially provided the platform 
from which support for the survivor's of abuse occurred (Charles, 2000). At another level, developments within contemporary social movements recognise the significance of small, diverse localised actions and organisations rather than a unified body as the way in which social action and change now occurs (Melucci, 1989). In this construction of social movements, the support for survivors has seen a widening base. In the UK, the mainstreaming of concern for domestic violence survivors has incorporated a broad base of professionals, and organisations from both the statutory and voluntary sector represented by more than 250 interagency forums across the country (Hague et al,1996). Many of these have now been transformed into active inter-agency groups against domestic violence with accountability within the broader but local, Crime and Disorder Reduction Partnerships.

While the representation of survivors of abuse may not be strong within these partnerships (Hague et al, 2003) and they are undoubtedly more conservative than the radical movement established by the second wave of feminism, they nevertheless often provide a commitment to keeping domestic violence (in particular) on the public agenda. This may not be 'the voice’ or the social movement which Herman (1992) might have originally envisaged, however, many of these partnerships are providing a very active and vocal local response to domestic violence with commitments to the crime and justice agenda as well as increasing the resources to survivors and some prevention programmes in schools. They are therefore not organisations which should be ignored in a discussion of the public face of the movement to support survivors. They generally compliment rather than contradict the work of the voluntary sector lobby groups striving to keep the needs of survivors on the social and political agenda. 
An aspect of these more professionally based forums are that they are more accessible to a wide range of people now working in the area of domestic violence intervention. They therefore open up a possibility for wider engagement of mental health professionals with the broader movement to support survivors. However, to date, mental health services, particularly psychiatrists and psychologists are rarely represented at these forums. Until this shift occurs, the disjuncture between services specialising in trauma counselling and the social movements and organisations which gives 'voice to the disempowered' will remain, in spite of a potentially more inclusive (and more conservative) social movement to support survivors of abuse.

\section{Conclusion}

Within any area of research, policy and practice dominant discourses become established and can be understood through the language which is used and adopted, who is allowed to speak with authority, and ideas and professional practices which gain ascendancy or are subjugated within these processes. Power relations adhere to these processes constructing the ways in which knowledge, policy and practice within a particular area develops (Weedon, 1987).

Tracing the developing discourse of PTSD shows a chequered history. While initially accepted as a legitimate description of the reactions for a significant group of war veterans, the road to recognition for survivors of trauma within the domestic sphere has been more contested. PTSD certainly seemed a preferable and more accurate description of severe emotional distress than the pejorative label of various forms of personality disorder which gave little or no indication of the intervention needs of the 
abuse survivor. However, in spite of recognition within the DSM-IV framework, there remains little evidence of the widespread circulation of this discourse in the psychiatric profession to support survivors. In contrast, clinical psychology has provided a 'home' for PTSD and the development of individual counselling services. The women's sector which both lobbies and provides services for survivors of genderbased violence have been ambivalent, and particularly wary about the role of the 'psy' professionals taking over and depoliticising the intervention for survivors.

There is nevertheless growing recognition (and demand by survivors) for an increase in counselling provision attached to women's services such as refuge, outreach and rape crisis organisations. This would include specific intervention to counter the impact of trauma. This process will be made easier, not just by increased resources, but also by a stronger connection by clinical services with ideas which have been marginalized within current trauma provision. These include the processes through which group support and the informal support networks around a survivor can be enhanced and developed and attention to posttraumatic growth rather than focusing on 'disorder'. It also includes the connection by mental health services with local domestic violence fora and other localised groups which now provide a significant aspect of the political and social response to violence against women in the home. Until these connections are made, the positive contribution of current clinical services to the recovery processes for survivors will remain in question.

\section{References}


Abrahams. Hilary. (2004). A Long Hard Road to Go By: A study of the Support Work Carried Out in Women’s Aid Refuges. PhD Dissertation, Bristol: Main Library, University of Bristol.

American Psychiatric Association. (1980). Diagnostic and Statistical Manual of Mental Disorders ( $3^{\text {rd }}$ edition, revised), American Psychiatric Association:

Washington D.C.

Andrews, Bernice., Brewin, Chris. and Rose, Suzanna. (2003). Gender, social support and PTSD in victims of violent crime. Journal of Traumatic Stress, 16, 421-427. Barron, Jackie. (2004). Struggle to Survive: Challenges for delivering services on mental health, substance misuse and domestic violence. Bristol: Women’s Aid Publications.

Babcock, Marguerite and McKay, Christine. (1995). Challenging codependency: Feminist Critiques. Toronto: University of Toronto Publications.

Batsleer, Janet., Burnman, Erica., Chantler, Khatidja., McIntosh, Hindene., Pantling, Kamal., Smailes, Sophie. and Warner, Sam. (2002). Domestic violence and minoritisation: Supporting women to independence. Manchester: Women’s Studies Research Centre, Manchester Metropolitan University.

Berg, Susan. (2002). The PTSD Diagnosis: Is it Good for Women?' Affilia, 17, 55-68. Bisson, Jonathan. and Shepherd, Jonathan. (1995). Psychological reactions of victims of violent crime. British Journal of Psychiatry, 167, 718-720.

Boscarino, Joseph. (1995). Post-traumatic stress and associated disorders among Vietnam veterans: The significance of combat exposure and social support. Journal of Traumatic Stress, 8, 317-336.

Brom, D., Kleber, R. and Defares, P. (1989). Brief psychology for posttraumatic stress disorders. Journal of Consulting and Clinical Psychology. 57, 607-612. 
Brown, L. (1995). Not outside the range. In Cathy Caruth (ed.), Trauma, Explorations in Memory. Baltimore: John Hopkins University Press.

Bhugra, Dinesh., Desai, M. and Baldwin, D. (1999). Attempted suicide in west $\underline{\text { London, rates across ethnic communities. Psychological Medicine, 29, 1125-1130. }}$

Burstow, Bonnie. (2003). Towards a radical understanding of trauma and trauma work. Violence Against Women, 9, 1293-1317.

Burstow, Bonnie. (1992). Radical Feminist Therapy: Working in the Context of Violence. Newbury Park: Sage.

Campbell, Jacquelyn. (1998). Making the Health Care System an Empowerment Zone for Battered Women: Health Consequences, Policy Recommendations, Introduction and Overview. In Jacquelyn Campbell. (ed.), Empowering Survivors of Abuse: Health Care for Battered Women and Their Children, London: Sage Publications. Carlson, B. (1997). A stress and coping approach to intervention with abused women. Family Relations, 46, 292-298.

Cascardi, Michele., O’Leary, Daniel., Schlee, Karin. (1999). Co-occurrence and correlates of posttraumatic stress disorder and major depression in physically abused women. Journal of Family Violence, 14, 227-249.

Charles, Nikki. (2000). Feminism, the State and Social Policy, Basingstoke: Macmillan.

Coker, A., Smith, P., Thompson, M., McKeown, R., Bethea, L. and Davis, K. (2002). Social support protects against the negative effects of partner violence on mental health. Journal of Women's Health and Gender-Based Medicine, 11, 465-476. Coid, Jeremy., Petruckevitch, Ann., Chung, Wai-Shan., Richardson, Jo., Moorey, Stirling., Feder, Gene. (2003). Abusive experiences and psychiatric morbidity in women primary care attenders. British Journal of Psychiatry, 183, 332-339. 
Davidson, Jonathan., Hughes, D., Blazer, D. and George, L. (1991). Post-traumatic stress disorder in the community: An epidemiological study Psychological Medicine 21, 713-721.

Davidson, Jonathan. and van der Kolk, Bessel. (1996). The psychopharmacological treatment of posttraumatic stress disorder. In Bessel van der Kolk, Alexander McFarlane, and L. Weisaeth (eds.), Traumatic Stress: The Effects of Overwhelming Experience on Mind, Body and Society, New York: Guildford.

Department of Health (2002). Women’s Mental Health: Into the Mainstream, London: Stationary Office www.dh.gov.uk/mentalhealth

Dutton, Mary-Ann. (1992). Empowering and Healing the Battered Woman: A Model for Assessment and Intervention. New York: Springer Publishing Co.

Flannery, Kate., Irwin, Jude. and Lopes, Angela. (2000). Connection and cultural difference: women, groupwork and surviving domestic violence. Women Against Violence, 9, 14-21.

Gleason, W. (1993). Mental disorders in battered women: an empirical study. Violence and Victims 8, 53-68.

Golding, Jacqueline. (1999). Intimate partner violence as a risk factor for mental disorders: A meta analysis. Journal of Family Violence, 14, 99-132.

Gondolf, Ed. (1998). Assessing Battered Women in Mental Health Services. Thousand Oaks, California: Sage.

Hague, Gill. Mullender, Audrey. and Aris, Rosemary. (2003). Is Anyone Listening? Accountability and Women Survivors of Domestic Violence. London: Routledge. Hague, Gill., Malos, Ellen. and Dear, Wendy. (1996). Multi-agency Work and Domestic Violence. Bristol: Policy Press. 
Herbert, Claudia. and Wetmore, Ann. (1999). Overcoming Traumatic Stress. London: Constable and Robinson.

Harvey, Mary. (1996). An ecological view of psychological trauma and trauma recovery. Journal of Traumatic Stress, 9, 3-23.

Herman, Judith. (1992). Trauma and Recovery. New York: Basic Books. Humphreys, Cathy. and Thiara, Ravi. (2002). Routes to Safety: Protection Issues Facing Abused Women and Children and the Role of Outreach Services. Bristol: Women's Aid Publications.

Humphreys, Cathy. and Thiara, Ravi. (2003). Domestic violence and mental health: 'I call it symptoms of abuse'. British Journal of Social Work, 33, 209-226.

Johnson, Holly. (1998). Re-thinking survey research on violence against women. In . Russell Dobash, and Rebecca Dobash, R. (eds.), Rethinking Violence Against Women, London: $\underline{\text { Sage Publications. }}$

Jones, Edgar., Vermass, Hodgins, McCartney, Helen., Beech, Charlotte., Palmer, Ian., Hyams, Kenneth. and Wessely, Simon. (2003). Flashbacks and post-traumatic stress disorder: the genesis of a $20^{\text {th }}$ century diagnosis. The British Journal of Psychiatry, 182, 158-163.

Jones, L., Highes, M. and Unterstaller, U. (2001). Post-traumatic stress disorder in victims of domestic violence: a review of the research. Trauma, Violence and Abuse 2, 99-119.

Joseph, Stephen., Williams, Ruth., \& Yule, William. (1993). Changes in outlook following disaster: The preliminary development of a measure to assess positive and negative responses. Journal of Traumatic Stress, 6, 271-279. 
Kemp, A., Green, B., Hovanitz, C. and Rawlings, E. (1995). Incidence and correlates of post-traumatic stress disorder in battered women: Shelter and community samples. Journal of Interpersonal Violence, 10, 43-55.

Laing, Lesley. (2001). Working with Women: Exploring Individual and Group Work Approaches. Issue Paper 4, Domestic Violence Clearinghouse, Sydney: University of New South Wales. www.austdvclearinghouse.unsw.edu.au.

Lindy, J. (1996). Psychoanalytic psychotherapy of post-traumatic stress disorder: The nature of the relationship. In Bessel van der Kolk, Alexander McFarlane and L. Weisaeth (eds) Traumatic Stress: The Effects of Overwhelming Experience on Mind, Body and Society, New York: Guilford Press, pp525-536.

Marmar, C., Weiss, D. and Pynoos, R. (1995). Dynamic psychotherapy of posttraumatic stress disorder. In Matthew Friedman, Dennis Charney and Ariel Deutch (eds.), Neurobiological and Clinical Consequences of Stress: From Normal Adaptation to Post Traumatic Stress Disorder. Philadelphia: Lippincott-Raven. Pp 495-50.

Marx, Gregory. and McAdam, John. (1994). Collective Behavior and Social Movements. Englewood Cliffs, NJ: Prentice Hall.

Melucci, Alberto. (1989). Nomads of the Present: Social Movements and Individual Needs in Contemporary Society. Hutchinson: Radius.

Mitchell, J. (1983). 'When disaster strikes.....The critical incident stress debriefing process. Journal of Personality and Social Psychology, 50, 1226-1234.

McFarlane, Alexander. (2000). Traumatic stress in the $21^{\text {st }}$ Century. Australian and New Zealand Journal of Psychiatry, 34, 896-902. 
McFarlane, Alexander. and Yehuda, Rachel. (2000). Clinical treatment of posttraumatic stress disorder: conceptual challenges raised by recent research. Australian and New Zealand Journal of Psychiatry, 34, 940-953.

Murphy, Patricia. (1997). Recovering from the effects of domestic violence:

Implications for welfare reform policy. Law and Policy, 19, 169-182.

Myhill, Andrew. and Allen, Jonathan. (2002). Rape and Sexual Assault of Women: The Extent and Nature of the Problem. Home Office Research Study 257, Findings from the British Crime Survey, 2002.

Profitt, Norma-Jean. (2000). Survivors of woman abuse: Compassionate fires inspire collective action for social change. Journal of Progressive Human Services, 11, 77102.

Rai, Dhanwant. and Thiara, Ravi. (1997). Re-defining spaces: the needs of black women and children in refuges support services and black workers in Women's Aid. Bristol, Women’s Aid Federation of England.

Resick, Patricia. (2001). Stress and Trauma. Hove: Psychology Press.

Resick, Patricia. and Jordan, C. (1988). Group stress inoculation training for victims of sexual assault: A therapist’s manual. In P. Keller and S. Heyman (eds.), Innovations in Clinical Practice: A Source Book, Sarasota, Fl: Professional Resource Exchange.

Sanders, Catherine. (1992). A long road home: working with survivors of child sexual abuse from a systemic perspective. Australian and New Zealand Journal of Family Therapy, 13, 16-25.

Saunders, D. (1994). Post-traumatic stress symptom profiles of battered women: a comparison of survivors in two settings. Violence and Victims, $\underline{\text { 9, 31-44. }}$ 
Sequeira, Heather. and Hollins, Sheila. (2003). Clinical effects of sexual abuse on people with learning disability: Critical literature review. British Journal of Psychiatry, 182: 13-19.

Shapiro, Francine. (1989). Eye movement desensitization: A new treatment for post traumatic stress disorder. Journal of Behaviour Therapy and Experimental Psychiatry, 20, 211-217.

Shapiro, Francine. (1995). Eye Movement Desensitization and Reprocessing: Basic Principles, Protocols and Procedures. New York: Guilford.

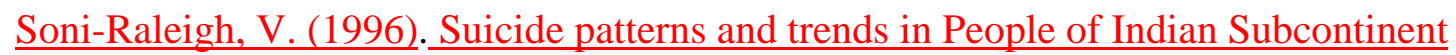
and Carribbean Origin in England and Wales. Ethnicity and Health, 1, 55-63.

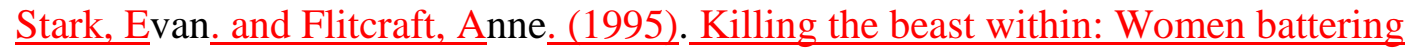
and female suicidality. International Journal of Health Services, 25, $43-64$. Taft, Angela. (2003). Promoting Women's Mental Health: The Challenges of Intimate/Domestic Violence Against Women. Issue Paper 8. New South Wales: Domestic Violence Clearinghouse. www.austdvclearinghouse.unsw.edu.au Tarrier, Nicholas., Sommerfield, C. and Pilgrim, H. (1999). Relatives’ expressed emotion (EE) and PTSD treatment outcome. Psychological Medicine, 29, 801-811. Tedeschi, Richard, \& Calhoun, Lawrence. (1995). Trauma and transformation: Growing in the aftermath of suffering. Thousand Oaks, CA: Sage Publications. Tedeschi, Richard, Park, Crystal, \& Calhoun, Lawrence (1998). Posttraumatic growth: Conceptual issues. In Richard Tedeschi, Crystal Park, \& Lawrence Calhoun (Eds.), Posttraumatic growth: Positive changes in the aftermath of crisis (pp.1-22). Mahwah, NJ: Lawrence Erlbaum Associates.

Tham, S., Ford, T. and Wilkinson, D. (1995). A survey of domestic violence and other forms of abuse. Journal of Mental Health, 4, 317-321. 
Thompson, Neil. (2002). Social movements, social justice and social work. British Journal of Social Work, 32, 711-722.

Trowell, Judith., Kolvin, I., Weeramanthri, T., Sadowski, H., Berelowitz, M., Glasser, D. and Leitch, I. (2002). Psychotherapy for sexually abused girls: Psychopathological outcome findings and patterns of change. British Journal of Psychiatry, 180, 234-247. Vostanis, Panos. (2002). Mental health of homeless children and their families.

Advances in Psychiatric Treatment, 8: 463-469.

Williams, J. and Copperman, J. (2002). Mental Health Services that Work for Women: Summary Findings of a UK Survey. Canterbury, The Tizard Centre: University of $\underline{\text { Kent. }}$

Weedon, Christine. (1987). Feminist Practice and Poststructuralist Theory. Oxford, Blackwell.

Yazdani, A. (1998). Young Asian women and self-harm: Mental Health Needs Assessment of Young Asian Women in Newham. Newham Innercity Multifund and Newham Asian Women's Project.

Zimmerman, M. and Mattia, J. (1999). Is posttraumatic stress disorder underdiagnosed in routine clinical settings? Journal of Nervous and Mental Disease, 187, 420-428. 


\section{University Library}

\section{- M M N E R VA A gateway to Melbourne's research publications}

Minerva Access is the Institutional Repository of The University of Melbourne

Author/s:

HUMPHREYS, CATHY;Joseph, Stephen

Title:

Domestic violence and the politics of trauma

Date:

2004

Citation:

Humphreys, C., \& Joseph, S. (2004). Domestic violence and the politics of trauma. Women's Studies International Forum, 27(5-6), 559-570.

Publication Status:

Published

Persistent Link:

http://hdl.handle.net/11343/34803 